REVISTA DE DERECHO UNED, NÚM. 17, 2015

\title{
LA ORDEN DE MALTA EN EL ORDENAMIENTO JURÍDICO INTERNACIONAL: EVOLUCIÓN HISTÓRICO-JURÍDICA
}

\author{
THE ORDER OF MALTA WITHIN THE INTERNATIONAL LAW: \\ HISTORICAL AND LEGAL EVOLUTION
}

\section{Marcos Fernández de Béthencourt}

Doctorando de la UNED

Máster en Derecho Nobiliario y Premial, Genealogía y Heráldica por la UNED

Abogado. Licenciado en Derecho, Ciencias Políticas y Derecho Canónico

Resumen: El presente trabajo expone un análisis de los conceptos de comunidad internacional, personalidad jurídica internacional, soberanía y sujetos sui generis de derecho internacional, para pasar a examinar la singularidad de la Orden de Malta y su relación con el derecho canónico. A continuación, se hace un repaso histórico de la evolución legal de la institución, desde su formación como comunidad de hermanos al cuidado del Hospital en Jerusalén, hasta convertirse en la actual Orden religiosa y sujeto soberano de Derecho Internacional Público, pasando sustancialmente por su reconocimiento como Principado soberano con base territorial, primero en la isla de Rodas y después en la isla de Malta, hasta su asentamiento actual en Roma. El estudio, pasa a continuación a exponer su organización actual y el contenido de su acción exterior o acción diplomática. Finaliza con unas conclusiones sobre el actual estado de la Orden en el contexto internacional.

Palabras clave: soberanía, personalidad jurídica, sujetos sui generis, Malta. 
Abstract: The present paper begins with an analysis of the concepts of International Community, legal international personality, sovereignty and international sui generis subjects; it examines the singularity of the Order of Malta and its link with canon law, since its inception as a brotherhood which handled the Hospital of Jerusalem, until its present situation as a religious Order and a sovereign subject of international law, mainly having been recognized as a sovereign Principality rooted first in the island of Rhodes and afterwards in the island of Malta until now, with its seat in Rome. It then reviews the historical legal evolution of the institution, to continue mentioning its present organization and the content of its diplomatic activity. Several conclusions about the present situation of the Order in the international context end it.

Keywords: sovereignty, legal personality, sui generis subjects, Malta.

Recepción original: 28/07/2015

Aceptación original: 01/09/2015

Sumario: I. Introducción. I.A. Concepto de Comunidad Internacional. I.B. Concepto de Personalidad Jurídica Internacional. I.C. Concepto de Soberanía. I.C.1 Sujetos sui generis de Derecho Internacional. I.C.2 Singularidad de la Orden de Malta. II. La Orden y su relación con el Derecho Canónico. III. La organización actual de la Orden de Malta como Sujeto de Derecho Internacional. IV. La acción exterior (la actividad diplomática). Evolución histórico jurídica. V. Conclusiones.

\section{INTRODUCCIÓN}

La Orden de Malta es un ente soberano, sujeto de Derecho Internacional que ocupa una posición única en el seno de la Comunidad Internacional y de la Iglesia Católica. Para entrar en el examen de su situación nos parece preciso exponer con carácter previo ciertos conceptos generales de Derecho Internacional Público que permitirán comprender mejor el verdadero alcance de su singular posición. No en vano, la Orden de Malta que hoy conocemos, es la heredera de más de 900 años de historia ininterrumpida, pero azarosa.

Estamos ante una Orden hospitalaria; referida no sólo a la actividad médica, sino también a la virtud de la hospitalidad; religiosa laical; siempre ha sido laica, aunque haya habido siempre sacerdotes en su seno y, hoy en día, pertenecen a la Orden religiosos profesos -la 1. ${ }^{\mathrm{a}}$ 
clase- junto con el resto de sus miembros laicos sin votos. Todos ellos sin vida en común, pero vinculados en mayor o menor grado con sus obligaciones cristianas y melitenses,

Es también una Orden de caballería; referida al espíritu caballeroso hacia los más débiles en servicio a Dios, y es tradicionalmente militar ${ }^{1}$. Ello es así, como consecuencia de los deberes de defensa de los peregrinos y la civilización cristiana en Tierra Santa y posteriormente en el Mediterráneo como potencia naval, que la Orden se vio obligada a asumir. No debe extrañarnos, incluso hoy en día, la unión de lo militar a lo religioso ya que Santo Tomás de Aquino ${ }^{2}$ enseñó, que puede fundarse una Orden religiosa para la vida militar, no con un fin temporal, sino para la defensa del culto divino, del bien público o de los pobres y de los oprimidos. A día de hoy esta función no exige la defensa con las armas de la fe o de los fieles, pero sí estar preparados para defender el desarrollo de la persona humana.

Finalmente, es también tradicionalmente nobiliaria; entiéndase que en época medieval la nobleza monopolizaba la función militar que la Orden se vio compelida a incorporar a sus fines. De ahí, el carácter nobiliario que la Orden mantiene por tradición. Esta cualidad nobiliaria de un buen número de sus miembros se entiende sustancialmente como compromiso de asunción de deberes por encima de derechos ${ }^{3}$.

Se trata pues de una institución de raíz medieval, probablemente la única que ha sobrevivido hasta nuestros días, como una realidad tan viva y pujante en el mundo. Institución que además de ser memoria viva, es una realidad influyente, como veremos a continuación. Lo es en el seno mismo de las naciones en las que desarrolla su labor y, lo es, en el seno de la Comunidad Internacional como tal. Es más, lo es también dentro de la Iglesia Católica, como una manifestación muy relevante de la misma.

Para que cuanto se expone a continuación, en relación a las características jurídicas e históricas de la Orden de Malta, no haga perder de vista la finalidad de la Orden y la razón de ser de toda su actividad

${ }^{1}$ El carácter militar de la Orden de Malta se lo reconoce el papa Alejandro VI por su Bula Cum Ordine Vestrum, de 11 de agosto de 1258 y los estatutos militares se perfeccionan con el Gran Maestre Hugo de Revel, en 1272.

${ }^{2}$ SANTO TOMÁS DE AQUINO. Suma Teológica, Parte II-II, Cuestión 188, artículo 3 .

${ }^{3}$ Soberana y Militar Orden Hospitalaria de San Juan de Jerusalén, de Rodas y de Malta, Reglamentos y Comentarios, promulgados por S. A. E. el Príncipe y Gran Maestre Frey Matthew Festing y aprobados por el Soberano Consejo el 18 de febrero de 2011. 
y proyección, no dejaremos de subrayar que ésta es promover la gloria de Dios, al servicio de la Fe y el Santo Padre y la ayuda al prójimo, mediante la santificación de sus miembros ${ }^{4}$. Dicho lo anterior, empezaremos por describir las características jurídicas del contexto internacional en el que la Orden se mueve hoy en día.

\section{I.A. Concepto de Comunidad Internacional}

La Comunidad Internacional es una sociedad descentralizada en la que no existe un poder central capaz de imponerse a las diversas soberanías estatales. Son los sujetos de Derecho Internacional, quienes elaboran las normas y quiénes son los destinatarios de las mismas. Los sujetos por antonomasia, son los Estados y las Organizaciones Internacionales (entendiendo por tales, las intergubernamentales, es decir, aquellas creadas principalmente por los Estados).

Además de los sujetos de derecho internacional, dentro de esta Comunidad Internacional, existen los actores internacionales que son de la más variada naturaleza; además de los Estados y las Organizaciones Internacionales intergubernamentales, encontramos las Organizaciones No Gubernamentales (ONGs), las empresas multinacionales, etc., así como otros sujetos de derecho internacional denominados sui generis. La diferencia entre el actor internacional y el sujeto de Derecho Internacional, es decir, entre los sujetos de las relaciones internacionales y los sujetos del Derecho Internacional es clara. El actor internacional es todo aquel que influye con su conducta y, a la vez, es determinado por las relaciones o dinámica de poder que se generan en la sociedad internacional. Sin embargo, el sujeto de Derecho Internacional, es toda persona jurídica e incluso física, titular de derechos y deberes derivados del Derecho Internacional. Sin embargo, como hemos dicho, aunque los sujetos básicos de Derecho Internacional son los Estados y las Organizaciones Internacionales (intergubernamentales). No obstante, veremos a continuación que hay más sujetos.

Así excepcionalmente están dotados de personalidad jurídica, entes que la doctrina denomina sui generis, y en esta categoría agrupa a todos aquellos que carecen de alguno de los requisitos exigidos para

${ }^{4}$ Artículo 2. Parágrafo 1, de la Carta Constitucional y Código de la Soberana y Militar Orden Hospitalaria de San Juan de Jerusalén, de Rodas y de Malta, promulgada el 27 de junio de 1961, reformada por el Capítulo General Extraordinario del 28-30 de abril de 1997, publicada en el Boletín Oficial de la Orden, número especial, de 12 de enero de 1998. 
ajustarse a la definición de personalidad jurídica internacional; como, entre otros, la Santa Sede, la Soberana Orden de Malta, y, en cierta medida, muy restringida, los pueblos no constituidos en Estado y los propios individuos respecto de los pocos derechos que el propio ordenamiento internacional les reconoce.

\section{I.B. Concepto de Personalidad Jurídica Internacional}

En la actualidad el concepto de personalidad jurídica en la Comunidad Internacional se atribuye a aquel ente que es titular de derechos y deberes u obligaciones originados por los Tratados y las costumbres internacionales; que son las fuentes del Derecho Internacional Público.

Pero con ser pacífico que los Estados y las Organizaciones Internacionales son en la actualidad los sujetos de Derecho Internacional por antonomasia, no es menos cierto, que coexisten con una gama de sujetos atípicos, que como hemos dicho, la doctrina ha dado en denominar sui generis. Estos últimos tienen una subjetividad internacional restringida en cuanto a capacidad, al ejercicio de derechos específicos y a la asunción de obligaciones concretas correlativas a esos derechos. Dentro de esta categoría tiende a incluirse a la Orden de Malta, pero expondremos porqué nos adherimos a aquellos autores que rechazan esa clasificación y defienden la categoría de ente único y atípico para definir o describir la naturaleza jurídica internacional de la Orden. Ni el Derecho Internacional, ni la práctica internacional, nos dicen cuáles son los entes con personalidad jurídica internacional y tampoco las hay que confieran determinados derechos a todo sujeto. El Derecho confiere personalidad a un ente confiriéndole derechos y obligaciones, pero no diciendo que es un sujeto de Derecho Internacional. Más aún, el Derecho Internacional no crea sujetos, son estos los que crean a aquel.

La doctrina general es que para ostentar la subjetividad internacional es preciso: 1 . Ser creadores de normas internacionales, 2 . Ser destinatarios de normas internacionales, 3. Incurrir en responsabilidad en caso de incumplimiento de sus obligaciones internacionales, y 4. Estar legitimados para presentar una reclamación internacional contra el autor de un hecho ilícito internacional.

Los sujetos tipo, primarios u originarios con subjetividad internacional plena son los Estados. Estos tienen una doble dimensión: son una realidad territorial y son una entidad política. Nacen a la vida de 
las formas más variadas: desmembramiento, recuperación de la independencia, división de estados, reunificación, unificación y continuación de la personalidad jurídica. No es relevante que el Estado haya sido reconocido o no formalmente por otros Estados, ya que este reconocimiento no es constitutivo. El reconocimiento es una constatación de un hecho preexistente. No hay además obligación alguna de reconocer. Los demás sujetos son derivados, es decir, que su subjetividad debe ser demostrada.

En Derecho Internacional general tampoco existe ninguna norma que atribuya a las Organizaciones Internacionales personalidad jurídica internacional, sino que se limita a dar a los Estados la competencia para crear una Organización Internacional y dotarla de personalidad jurídica. El fundamento de su personalidad se localizaría en el Tratado constitutivo de la Organización Internacional. Son creadas por Estados principalmente, pero no exclusivamente. No suelen tener personalidad jurídica internacional reconocida en sus Tratados constitutivos; esta se presume en virtud del Dictamen de 1949 del Tribunal Internacional de Justicia (TIJ) ${ }^{5}$. Hacemos esta precisión debido a que hay autores que clasifican a la Orden de Malta como una Organización Internacional.

No son territoriales, sino funcionales. El dato básico es el de su funcionalidad. Tienen capacidad jurídica parcial según sus fines y, relativa, ya que necesita ser reconocida para poder mantener relaciones con Estados no miembros de la Organización Internacional. A este respecto, es básico empezar por señalar que el fundamento de la personalidad jurídica de las Organizaciones Internacionales, es el citado Dictamen del TIJ, de 11.04.1949, sobre reparación de daños sufridos al servicio de la Naciones Unidas. En él, se fija hasta el día de hoy, la doctrina de Derecho Internacional en virtud de la cual:

"Los sujetos de derecho, en un sistema jurídico no son necesariamente idénticos en cuanto a su naturaleza o la extinción de sus derechos; y su naturaleza depende de las necesidades de la Comunidad.»

Y añade:

"Mientras que un Estado posee, en su totalidad, los derechos y deberes internacionales reconocidos por el Derecho Internacional, los derechos y deberes de una Organización Internacional deben depender de los fines y funciones de aquélla, enunciados o implícitos en su acto constitutivo y desarrollados en la práctica...»

\footnotetext{
${ }^{5}$ http://www.icj-cij.org/homepage/sp/files/sum_1948-1991.pdf, págs. 19-20.
} 
O lo que es lo mismo, rompe el monopolio de la subjetividad internacional y admite por primera vez grados en la capacidad de los sujetos. El Estado dejó de ser un modelo. Pero es importante tener claras ciertas características de la subjetividad internacional:

- La subjetividad internacional es absoluta, no se puede ser sujeto de Derecho Internacional parcialmente. En otras palabras, se es sujeto internacional o no. Este principio, es determinante para entender que las posturas que propugnan una suerte de personalidad jurídica disminuida para la Orden de Malta, carecen del mínimo rigor conceptual exigible al abordar este punto.

- Es indispensable que algún otro sujeto de Derecho Internacional le reconozca como tal. La Orden de Malta está reconocida, en todo caso, por la Santa Sede.

- La capacidad jurídica o de goce internacional (aptitud para ser titular de derechos y deberes jurídicos internacionales) es distinta de la subjetividad internacional. Una distinción más que pertinente, para no confundir la plenitud de la personalidad o subjetividad internacional con su mayor o menor capacidad.

La capacidad jurídica es relativa, ya que los sujetos de Derecho Internacional pueden tener más o menos capacidad según los derechos o deberes de los que son titulares. Por ello, la capacidad la determinan los textos que la establecen.

- La capacidad es la posibilidad de alcanzar acuerdos regidos por el Derecho Internacional. Disponer de un cierto grado de ius representationis. Poder acceder a instancias internacionales para ejercer su derecho de reclamación. Ejercer ciertas competencias atribuidas por normas internacionales. Poder incurrir en responsabilidad internacional. Aplicar las normas de la guerra (conflicto armado) en caso de participar en ella.

— La subjetividad internacional de los sujetos del ordenamiento internacional se rige por principios distintos, según de qué tipo sean los mismos. Cuando se trata de Estados, para determinar cuando son tales, se acude al principio de soberanía, es decir, la independencia para tomar resoluciones.

Por otra parte, el sujeto de Derecho Internacional debe demostrar esa condición en la práctica y, para ello debe ser capaz de celebrar Tratados, debe poder ser parte en una relación de responsabilidad (por activa, exigiendo y, por pasiva, sufriendo su exigencia) ante ese 
Ordenamiento Jurídico Internacional y debe tener capacidad para entablar relaciones diplomáticas con el resto de los sujetos.

\section{I.C. Concepto de Soberanía}

La noción de soberanía se desarrolla con el abandono de la referencia a Dios, surge de la eliminación de la referencia cristiana a lo divino. Es la transposición del concepto formulado en el siglo XVI de la summa potestas, poder absoluto y perpetuo del Rey que hoy viene sustituido por el Estado ${ }^{6}$. La soberanía es la expresión de una voluntad de ser el propio dueño y señor y de un poder, el de la «nación» de fijar libremente y sin condicionamientos exteriores las reglas que determinan el comportamiento de un gobierno y la vida de los que constituyen dicha nación ${ }^{7}$. Se podría resumir en independencia y autonomía. La soberanía era la voluntad del soberano que no reconoce superior y es el fundamento del Estado. La soberanía entre Estados significa la independencia; en una parte del territorio en la que la ejerce por derecho y con exclusión de todo otro Estado. La independencia implica al propio tiempo exclusividad, autonomía y plenitud de competencias o jurisdicción sobre un territorio y población. La exclusividad, significa que sólo el Estado ejerce esas competencias. La autonomía, significa competencia discrecional; libertad para decidir las decisiones a tomar. La plenitud, significa ausencia de limitación en la competencia a ejercer válidamente en el territorio en cuestión ${ }^{8}$.

Estos elementos se traducen en:

- Una igualdad jurídica dentro de la Comunidad Internacional con independencia de su posición económica, etc.;

- capacidad de autogobierno, sin intervención o injerencia de otros Estados (superiorem non recognoscens);

- independencia con exclusividad, autonomía y plenitud, para fijar su política interior y exterior de forma autónoma;

- ius legati, la capacidad activa y pasiva de tener órganos de representación en el exterior y de recibirlos en su territorio;

- territorio propio, donde se aplica con carácter excluyente su propio ordenamiento jurídico, y

${ }^{6}$ KNOPF-SILVESTRE, Frédérique. L'Ordre Souverain de Malte en Droit International Public, Tolouse, 2000.

${ }^{7}$ ISOART, Paul. La Souveraineté Republicaine, Paris, 1990, pág. 178.

${ }^{8}$ ROUSSEAU, Charles. Droit International Public, Paris, 1993, pág. 90-92. 
- un ordenamiento jurídico como tal, que es el derecho interno que rige en su país, cuya fuente es la legislación interna.

Esta soberanía implica la igualdad jurídica en derechos y obligaciones (Principio Fundamental recogido en la Carta de las Naciones Unidas (art. 2.1.) y en la Declaración Aneja a la Resolución 2625 (XXV), de 24.10.1970, de la Asamblea General, que recoge éste como uno de los siete principios. Esta noción de soberanía es una noción política y discutible. Lo cierto, es que no existe un concepto de independencia puro y simple. La igualdad entre los Estados es irreal y se debe a la efectiva desigualdad entre ellos en poder, desarrollo, economía, etc. Por ello, invocar el territorio como soporte de la soberanía resulta hoy en día exiguo.

Es además soberano, el ente unitario que se afirma desde el principio en el ejercicio de sus poderes como independiente del exterior, es decir, de ningún otro poder. Su poder soberano consiste en poder regular las relaciones sociales internas de su comunidad y dirigirse por sí. Ejercitar funciones de naturaleza soberana no solo formalmente sino sustancialmente. El ordenamiento melitense es precisamente un orden completo del que emanan las reglas de su vida interna y las de sus miembros en cuanto tales o en contacto con terceros. Sus fines institucionales se realizan a través del ejercicio de sus poderes y funciones típicas de todo ente soberano. Hoy, la Orden tiene las tres funciones fundamentales de la soberanía: normativa, ejecutiva y jurisdiccional y, de ahí, que no pueda negársele la soberanía ${ }^{9}$. Existe un sector de la doctrina que sostiene tesis contrarias a la soberanía de la Orden de Malta. Así, entre otros, d'ESZLARY ${ }^{10}$, cree que es una organización derivada de la Santa Sede y que su soberanía está emanada de la misma. BERNARDINI ${ }^{11}$ niega incluso la autonomía de la Orden y la considera incluida plenamente en el ordenamiento canónico. OTTAVIANI considera a la Orden como un ente descentralizado de la Santa Sede. BISCOTINI ${ }^{12}$ sostiene que la Orden carece de una organización social efectivamente independiente y que el número de sujetos que la reconocen es escaso, lo que, según él, prueba la debilidad de su autonomía erga omnes.

${ }^{9}$ MONACO, Riccardo. Considerazioni sulla sovranità ll'Ordine Gerosolimitano di Malta.

${ }^{10}$ D'ESZLARY, Charles. "La situation juridique internationale de l'Ordre Souverain de Malte», en Revue Administrative, (1958), págs. 72-79.

${ }^{11}$ BERNARDINI, Andrea. "Ordine di Malta e diritto internazionale», en Rivista di Diritto Internazionale, 50, (1967), págs. 497-562.

${ }^{12}$ BISCOTTINI, Giuseppe. Sulla condizione giuridica dell'Ordine di Malta, Archivo Histórico de Malta, X, (1939), págs. 1-16. 
Un argumento fundamental suscitado en apoyo de estas tesis, lo era la aprobación de la Santa Sede a la elección del Gran Maestre de la Orden. Al haber desaparecido hoy ese poder vicario que se le atribuía a la Santa Sede, el argumento carece de fundamento alguno, habida cuenta la reforma de la Carta Constitucional y el Código en $1997^{13}$, donde entre otros puntos, se suprime dicha aprobación papal, residenciándose la decisión última a este respecto, en la propia Orden.

Por otra parte, los 106 Estados que, a día de hoy, reconocen a la Orden de Malta como sujeto de derecho internacional y las numerosas Organizaciones Internacionales con las que tiene suscritos Tratados, echan por tierra la argumentación sobre la «debilidad» de su autonomía en el plano internacional. Nótese que está incluso «sentada» en la ONU como Observador Permanente ${ }^{14}$. Esto constituyó un hito en la historia diplomática de la Orden. Este poder soberano se manifiesta como poder normativo y judicial emanando y aplicando normas que regulan las relaciones entre sus miembros y como poder de gobierno y administrativo.

Siguiendo a PEZZANA ${ }^{15}$, podemos decir que la Orden de Malta tiene un sistema jurídico propio, complejo, expresado por la Carta y el Código y por las leyes y reglamentos. Todas estas normas regulan la Orden y el funcionamiento de sus instituciones, los deberes y derechos de sus miembros y regulan el desarrollo de sus relaciones jurídicas en razón de su pertenencia a la Orden así como el poder judicial constituido por los Tribunales Magistrales.

${ }^{13}$ Carta Constitucional y Código de la Soberana y Militar Orden Hospitalaria de San Juan de Jerusalén, de Rodas y de Malta, promulgada el 27 de junio de 1961, reformada por el Capítulo General Extraordinario del 28-30 de abril de 1997, publicada en el Boletín Oficial de la Orden, número especial, de 12 de enero de 1998.

${ }^{14}$ Resolución 48/265 de concesión del estatuto de Observador Permanente, Acta de la 48. ${ }^{a}$ Asamblea General Plenaria de 24 de agosto de 1994, punto 180 del Orden del Día, en Carlo MARULLO DE CONDOJANNI, Il Sovrano Militare Ordine di Malta, Osservatore Permanente alle Nazione Unite, Testimonianze, Palermo, 2008, pág. 77. La resolución se adoptó por consenso, al apoyarla 65 Estados y con la oposición (fundamentalmente, por carecer de un territorio y un pueblo) de EE.UU., R.U., Rusia, China y Francia. Fruto de muchos años de negociación, se obtuvo ese puesto (Observador Permanente) en la Asamblea General, que no estaba previsto en la Carta de las Naciones Unidas, pero había sido instituido en 1948, cuando fue invitada a participar en los trabajos de la ONU, sin derecho a voto, la Confederación Helvética, que no quería entrar como miembro efectivo, por temor a que se resintiese su historia política de neutralidad.

${ }^{15}$ PEZZANA, Aldo. Il fondamento giuridico e storico della sovranità dell'Ordine Gerosolimitana de Malta, Roma. 
Para mayor clarificación sobre la vinculación que se hace del concepto de soberanía con la posesión de un territorio, señalaremos un hecho incontestable que desmonta tal afirmación. Ya en 1530, vemos, que el primer Tratado internacional que la Orden de Malta firma, lo hace careciendo de territorio, pues, ya había perdido Rodas y lo hace con el Emperador Carlos V y la Reina Juana, a título de Reyes de Sicilia, para la cesión a la Orden de las islas de Malta y Gozo junto con los islotes de Comino y San Pablo, además de la ciudad de Trípoli, en calidad de feudo exclusivo y soberano de los Caballeros. Concretamente podrían acuñar moneda propia, nombrar embajadores y ejercitar derechos inalienables sobre dichos territorios, aceptándose que los Grandes Maestres fueran príncipes de las tierras concedidas, sólo pagaban un tributo anual consistente en un halcón por la fiesta de Todos los Santos al Rey de Aragón ${ }^{16}$. Se podrá argüir que el Gran Maestre «dependía» del Emperador a título de Príncipe del Sacro Imperio Romano, pero parece claro que su subjetividad sin territorio ya estaba clara en 1530. Es más, la Santa Sede continuó manteniendo relaciones con la Orden como tal sujeto de Derecho internacional.

Sería difícil aplicar hoy en día a la Orden los conceptos actuales de Estado o de soberanía, ya que son conceptos variables y que, desde luego, no existían en el siglo XII, en el cual sí se mantenía la idea de universitas cristiana o de res publica cristiana, con el Papa y el Emperador como doble cabeza del orden universal. Como dijimos estamos ante un instituto medieval. De hecho, al recibir la isla de Malta, los Caballeros se negaron a prestar juramento de fidelidad al Emperador porque podría simbolizar un vínculo de obediencia militar que afectaría a la autonomía de las decisiones de la Orden. De ahí, que definiesen sus relaciones vasallático-militares como simple y ordinaria parte del juramento de los Caballeros de no tomar armas contra reinos cristianos.

Así quienes califican de mera cortesía el reconocimiento de la Orden por parte de la República de Italia, donde se encuentra enclavada la sede de la Orden, quedan igualmente desmentidos sin necesidad de mayor argumentación, con la firma del último Tratado bilate-

${ }^{16}$ Este tributo no representaba una pérdida de soberanía y baste citar como ejemplo, el caso del reino de Portugal reconocido por el Papa Alejandro III en 1179 como país independiente y vasallo de la Iglesia o en el siglo XIII en que el rey de Granada AlAhmar presta vasallaje a Fernando III de Castilla y se obliga a pagar tributo hasta la década previa a su conquista, dos siglos después; ello sin menoscabo de su soberanía. Este tributo simbólico no hizo que jamás nación alguna pusiera en duda el ejercicio efectivo de los poderes típicos de la soberanía y la completa libertad de autodeterminación en todo lo que no fuese materia estrictamente religiosa de la Orden de Malta. 
$\mathrm{ral}^{17}$. Los que pretenden equiparar a la Orden con una Organización Internacional a nuestro juicio pecan de inconsistencia ya que como ente primario que es, tiene una subjetividad similar a la de los Estados, basada en la autonomía e independencia recíprocas, aunque carezca de territorio. Precisamente el reconocimiento de su «estado anfitrión», la República de Italia, así lo confirma. Nadie estaría, en principio, más interesado en restarle capacidad que Italia. La soberanía equivale a independencia o exclusión de injerencia en sus asuntos internos por terceros y el reconocimiento como sujeto internacional, pero el reconocimiento es declarativo, no constitutivo, es un acto político realizado con elementos jurídicos o formales. El principio derivado de inmunidad de jurisdicción y de ejecución tiene en cambio su fundamento en el derecho internacional consuetudinario. En su vertiente personal afecta a ciertos órganos; el Jefe del Estado, los Presidentes de Gobierno y más limitadamente a los Ministros de Asuntos Exteriores. En la jurisprudencia española está plenamente reconocida.

Los agentes diplomáticos tienen la inviolabilidad personal plenamente reconocida a través de la Convención de Viena sobre relaciones diplomáticas 1961 y la Convención sobre la Prevención y el castigo de delitos contra personas internacionalmente protegidas, inclusive los agentes diplomáticos de 1973, que otorga una protección especial al diplomático, su familia y su residencia, documentos y bienes. La Orden no sólo está reconocida por el Reino de España y mantiene plenas relaciones diplomáticas a nivel de embajador, también los Tribunales le reconocen la inmunidad a sus agentes diplomáticos de nacionalidad española ${ }^{18}$.

${ }^{17}$ Con la República de Italia la Orden siempre fue tratada como sujeto de Derecho Internacional, pero no se definieron las relaciones diplomáticas de forma precisa, aunque se mantenían por intercambio de Notas Diplomáticas (acuerdo simplificado) de 1956 y 11 de enero de 1960. En 1980 se elevaron las representaciones respectivas al rango de embajada. El 13 de julio de 2005 se clarificó el uso de la matrícula SMOM. Pero será por el Tratado suscrito con fecha 17 de mayo de 2012, que entró en vigor el 12 de diciembre de 2012, por el que se reconozca formalmente el derecho de legación activa y pasiva con inmunidad diplomática para los agentes acreditados ante la Orden. Si bien un Protocolo Adicional prevé un parecer vinculante de la República de Italia para autorizar apertura de sedes por terceros países sin representación ante Italia. Básicamente es para evitar asumir cargas ajenas, al constituir las sedes de la Orden un enclave en Italia. Por ello, la costumbre de acreditar a los embajadores que ya lo son ante la Santa Sede o ante la República de Italia. Hoy se puede afirmar que el estatus de las relaciones entre ambas partes es de Derecho Internacional pleno.

${ }^{18}$ El Tribunal Supremo (Sala de lo Contencioso-Administrativo), en sentencia de 5.07.2003, confirma la sentencia previa de la Audiencia Nacional, que declaraba que el esposo de la recurrente mantenía en los ejercicios fiscales discutidos, la condi- 


\section{I.C.1 Sujetos sui generis de Derecho Internacional}

Los sujetos sui generis, es el grupo compuesto por aquellos sujetos que no cumplen alguno de los requisitos esenciales de un Estado soberano. Por ejemplo, Estados con subjetividad internacional parcial; se le podría reconocer al miembro de una confederación por venir limitado por el propio ordenamiento jurídico que le da tales facultades. Los mini-estados por no contar con capacidad plena para establecer relaciones internacionales y necesitar de otro Estado. Aparte de estas variedades estatales, estarían hoy en día:

Las personas físicas o individuos, que también son titulares directos de ciertas responsabilidades y derechos en el campo del Derecho Internacional. Las personas jurídicas: Las Organizaciones No Gubernamentales (ONG) se diferencian de las Organizaciones Internacionales en que no nacen de un Tratado entre Estados, sino que su base jurídica es un acto de Derecho interno, aunque despliega sus efectos en el plano internacional. Ciertas empresas inter o supra-nacionales: las hay que constituidas sobre la base de Tratados bi o multinacionales prestan servicios públicos bajo régimen internacional y algunas tienen reconocida subjetividad internacional. Ciertos bancos, por ejemplo el Banco Internacional de Reconstrucción y Fomento (BIRD). El Comité Internacional de la Cruz Roja (CICR): Esta ONG es la excepción que ve reconocidas sus atribuciones en virtud de Tratados o derechos susceptibles de ejercerse en el plano internacional por razón de los Convenios de Derecho Internacional aplicables a los conflictos armados. Los Beligerantes e Insurrectos, los Movimientos de Liberación Nacional, los Refugiados y los Gobiernos en el exilio. Finalmente estaríamos frente a tres entes vinculados a la actividad religiosa y concretamente católica.

La Santa Sede, constituida por el Papa y los organismos superiores de la Curia Romana. Este es un ente originario de la sociedad internacional y primus inter pares durante la Res Publica Gentium Christianorum. Después de la unificación italiana sigue gozando de personalidad jurídica internacional sin territorio. Así en la Ley italiana de Garantías de 13.5.1871 y en los Concordatos con distintos Estados y para la mayoría de los Estados, al mantener relaciones diplomáticas con la Santa Sede, hasta el Tratado de Letrán de 11.2.1929. Participa activamente en la vida internacional y en la elaboración de las normas internacionales. El Estado de la Ciudad del Vaticano, sin

ción de embajador extraordinario y plenipotenciario de la Orden y, en consecuencia, le era aplicable el Convenio de Viena de 18.04.1961. 
representantes diplomáticos puede, no obstante, cerrar Tratados y ser miembro de Organizaciones Internacionales. Es también un Estado aunque tenga conferidas sus relaciones internacionales a la Santa Sede. Algunos Estados sólo reconocen el Estado de la Ciudad del Vaticano y otros sólo a la Santa Sede.

La Soberana Orden de Malta sujeto atípico neutral, apolítico e imparcial en la política internacional, es un ente con ordenamiento propio, aunque vinculado a la Santa Sede en cuanto Orden religiosa.

Cuando se afirma que el ordenamiento jurídico de la Orden de Malta es originario es porque ha sido creado por ella misma y para sí misma, es decir, que es una fuente autónoma de su propio ordenamiento y al propio tiempo es independiente, ya que nace y permanece libre de todo condicionamiento externo. Por consiguiente, halla su fuente última de validez en sí mismo ${ }^{19}$.

El hecho internacionalmente determinante es el carácter originario del ordenamiento jurídico melitense, que no deriva de otro derecho y nace del propio poder normativo de la institución. La prueba la encontramos en que sus normas son válidas y eficaces en su ámbito de aplicación sin necesidad de ratificación por autoridad externa a la Orden. Hay, como hemos dicho, una organización institucional similar a la estatal; legislativa, gubernativa y jurisdiccional ${ }^{20}$. En la base de la Orden está el proceso formativo mediante el cual a través del tiempo ha dado lugar a la instauración de un ente de caracteres análogos a los de un Estado y es ese proceso formativo lo que ha dado lugar a la base social del actual orden jurídico de la Orden de Malta. Por ello, procedería su soberanía no tanto de que coincida con un ordenamiento jurídico originario, sino más bien de que la Orden estuvo dotada de un poder soberano originario ${ }^{21}$. Con independencia del enfoque doctrinal sobre el carácter de la soberanía de la Orden, lo que nos parece incuestionable es su condición de sujeto de Derecho Internacional derivada de su actuación en el seno de la Comunidad Internacional. Sin embargo, creemos con $\mathrm{MONACO}^{22}$, que no es un sujeto sui generis, sino un sujeto primario de Derecho Internacional. El término sui generis es un término equívoco, como veremos a continuación y de ahí, que creamos que deba ser rechazado.

${ }^{19}$ SANDONATO DE LEÓN, Pablo José, «La Soberana Militar Orden de Malta en el orden jurídico internacional», en Ius Canonicum, 87, (2004), págs. 208-231.

${ }^{20}$ Ibid, págs. 208-231.

${ }^{21}$ Ibid, págs. 208-231.

22 MONACO, Riccardo. "Osservazioni sulla condizione giuridica internazionale dell'Ordine di Malta», en Rivista di diritto internazionale, 64, (1981), págs. 15-29. 
La Orden nace de un proceso histórico en el cual las fuerzas sociales que constituyen su base han adquirido un carácter concreto. Por eso, su nacimiento no coincide con su constitución formal. Como expusimos al principio, tiene una vocación universal. Puede ser comparada a un Estado, aunque creemos que no totalmente asimilada. Sus fines son más amplios que los humanitarios y por su propia naturaleza no están limitados. Es una institución con una esfera ilimitada de competencias y de actuación. Desde luego tiene la capacidad para tener un territorio aunque no lo tenga y una Organización Internacional no ${ }^{23}$. Tampoco es una Organización Internacional, las Organizaciones Internacionales están siempre limitadas por el principio de especialidad, no pudiendo por ello exceder de sus funciones como Organización. Entre otras razones de peso, la Orden no nace de un Tratado o Convención alguna.

La Orden es un caso atípico, nunca ha renunciado a su soberanía. Es un sujeto de Derecho Internacional único y frente a quienes impugnan su personalidad jurídica, la Orden opone la realidad de su reconocimiento internacional por parte de Estados y Organizaciones Internacionales. La base actual de su expansión diplomática es la neutralidad e independencia. Entendemos que no se debe aceptar el término sui generis, sino el de institución soberana, sujeto primario de Derecho internacional, sin someterse ni a la ONU para recibir una calificación jurídica exacta.

\section{I.C.2 Singularidad de la Orden de Malta}

El Derecho Internacional moderno admitió la existencia de la Soberana Orden de Malta como un sujeto constituido conforme a las normas vigentes antes de su formación, reconociéndole una personalidad jurídica propia, equivalente a la de los Estados. La Orden está fuera del esquema jurídico tradicional y representa un caso único que excluye toda clasificación, salvo la que proviene de sus estatus singular. La Orden ha gozado de personalidad jurídica internacional y ha sido tratada como ente soberano por los Estados desde que la Comunidad Internacional existe en el sentido medieval y en el sentido moderno de la expresión, es decir, desde el siglo XVIII.

La personalidad jurídica internacional de la Orden no ha sufrido cambio como consecuencia de la pérdida del archipiélago de Malta, y

${ }^{23}$ PEZZANA, Aldo. Il fondamento giuridco e storico della sovranità dell'Ordine di Malta, Roma. 
así se desprende del reconocimiento por parte de los Estados y las estrechas relaciones que mantienen con ellos. Es opinión mayoritaria que la Orden continuó siendo reconocida en el periodo posterior a la salida de la isla de Malta en cuanto tal Orden y no como gobierno en el exilio. Ello justificaría la continuidad de las relaciones diplomáticas con buen número de las naciones que formaban la Comunidad Internacional en aquel momento. Época en la que no se conocían otros sujetos de Derecho Internacional que los Estados y el propio ordenamiento o doctrina excluía las relaciones con otros entes que no fueran estatales. Su reafirmada independencia interna fue el título que legitimó la persistencia de su personalidad jurídica internacional y en particular ante la Santa Sede. Ha estado siempre dotada de su propia individualidad permanente ${ }^{24}$. La eficacia de su ordenamiento perfectamente autónomo es su fundamento y al no derivar del exterior es por lo que puede considerarse originario. La Orden ha suscrito numerosos Acuerdos Internacionales y lo sigue haciendo en épocas muy recientes, contribuyendo con ello a la creación del Derecho Internacional. En la práctica las teorías jurídicas que puedan explicar su realidad son realmente secundarias para la Orden, ya que lo sustancial es la realidad de las relaciones efectivas de tipo político y jurídico que la Orden mantiene con numerosísimos Estados. Doctrinalmente se puede hablar de la teoría del ordenamiento jurídico originario de carácter no estatal, de la teoría de la soberanía instrumental para la realización de un fin religioso y humanitario de la Orden o de la teoría de la existencia de una norma internacional de ius singulare que atribuye soberanía a la Orden como sujeto de Derecho Internacional sui generis ${ }^{25}$.

Es un hecho, que la Orden de Malta, disfruta del derecho de legación activa y pasiva y de la capacidad de suscribir Tratados en pie de igualdad con los restantes Estados. Por ejemplo, el Comité Internacional de la Cruz Roja es un ente internacional que deriva de los Tratados que lo crean y le atribuyen competencias. La Orden de Malta es un sujeto soberano que no procede de ninguna convención internacional. La Orden no sólo no es objeto del Derecho Internacional, sino que contribuye a la formación de dicho Derecho Internacional como sujeto en paridad con los Estados, en las convenciones internacionales que suscribe. Lo que no puede negarse es que la Orden actúa ininterrumpidamente en el orden jurídico internacional desde la génesis de éste, de ahí, que no quepa cuestionar si debe o no reconocérsele su personalidad jurídica, puesto que siempre gozó de ella. No puede bus-

${ }^{24}$ PÉREZ PEÑA, Rafael. op. cit., págs. 41-101.

${ }^{25}$ PEZZANA, Aldo. op. cit., págs. 35-36. 
carse analogía alguna de la Orden de Malta con ninguno de los sujetos de Derecho Internacional moderno. Su naturaleza jurídica interna es ajena a ese orden jurídico, si bien reconocida por éste consuetudinariamente. De ahí, que el reconocimiento de su subjetividad sea doble; tiene como origen el consuetudinario y los Tratados que suscribe sólo tienen como efecto dar carta de naturaleza al reconocimiento consuetudinario previo.

\section{LA ORDEN Y SU RELACIÓN CON EL DERECHO CANÓNICO}

Para poder describir la situación actual de la Orden de Malta no se puede omitir un análisis de su situación como Orden caballeresca religiosa laical. Coincidimos con $\mathrm{GAMBI}^{26}$ en que la Orden es independiente en la Iglesia y no de la Iglesia Católica y su propia y profunda naturaleza rechaza cualquier género de categorización canónica codicial, dentro del ordenamiento jurídico eclesiástico actual. Tiene una categoría canónica peculiar y única. Hoy en día las Órdenes caballerescas no tienen, como tales, un lugar preciso en el Código de Derecho Canónico o Codex ${ }^{27}$, éste no las menciona, como tampoco a las Congregaciones. Habría, a tenor del mismo, que encuadrarlas en la categoría de asociaciones públicas o bien asociaciones privadas de fieles o, en su caso, dentro de los institutos de vida consagrada. Lo cierto es que ninguna de estas categorías permite ubicar a la Orden de Malta dentro del Codex. La singularidad de la Orden no sólo se produce en el campo del Derecho Internacional Público, como hemos visto, sino que se da por igual en el campo canónico. Así, incluso a los profesos o Caballeros de Justicia, que sería el único colectivo de la Orden equiparable por sus votos, a los religiosos regulados en el Codex (cánones 573 y 607 a 709), también les falta un elemento, para que precisamente esa Primera Clase de la Orden, pueda ser considerada un Instituto Religioso de los previstos en el canon 709.2; ya que los Caballeros de Justicia no tienen vida en común desde hace siglos.

Sin ánimo de extendernos, pero sí de precisar la particular naturaleza canónica de la Orden, en la medida en que influye en su posición dentro de la Comunidad Internacional, creemos que la Orden se asemeja más a un instituto secular de los regulados en los cánones 710 a 730, dejando siempre a salvo el colectivo de miembros que integran la Primera Clase, que son religiosos a todos los efectos, aunque no

\footnotetext{
${ }^{26}$ GAMBI, Paolo. "La Soberana Orden de Malta en el orden jurídico eclesial», en Ius Canonicum, 87, (2004), págs. 198-207.

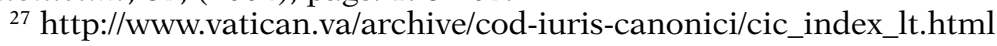


hagan vida común. Ello, porque está constituida por fieles que viviendo en el mundo, se dedican a procurar su santificación desde dentro de él, si bien con diferentes niveles de compromiso, según pertenezcan a la Segunda Clase; donde emiten promesa de Obediencia ${ }^{28}$ o a la Tercera Clase, donde adquieren un compromiso por la Orden y la Iglesia, observando una conducta cristiana y cooperando en las obras de asistencia melitense ${ }^{29}$.

La Santa Sede a través de su Anuario Pontificio ${ }^{30}$, en su edición de 2015, sigue un criterio histórico jurídico de precedencia en la clasificación de los Institutos de Vida Consagrada, colocando a las Órdenes en primer lugar y a las Congregaciones a continuación. Por cierto, que en dicha publicación la Orden no aparece relacionada en ese capítulo, sino a través de su representación diplomática, dentro del elenco del Cuerpo Diplomático acreditado ante la Santa Sede. En consecuencia, la Orden de Malta no es una persona moralis Ecclesia, es decir, un simple instituto religioso, y sólo tiene una relativa dependencia en el plano interno en materia religiosa, si bien exentos de la jurisdicción de las diócesis y dependiendo directamente de la Santa Sede. Es decir, gozando de una autonomía casi única en el panorama eclesiástico. Todo ello sobre la base de una total y absoluta independencia de la Orden en el plano internacional, reconocida así por la propia Santa Sede, que recibe y acredita un embajador ante sí y nombra un Cardenal Patrono ante la Orden. Siguiendo al citado GAMBI ${ }^{31}$, consideramos que la Orden de Malta constituye una categoría en sí misma, modelo hibrido de una entidad soberana medieval y de una orden caballeresca, dotada de una independencia en materia temporal, suficiente para permitirle ejercitar en todos los aspectos la potestad propia de un sujeto de derecho internacional contemporáneo.

${ }^{28}$ Soberana y Militar Orden Hospitalaria de San Juan de Jerusalén, de Rodas y de Malta, Reglamentos y Comentarios, promulgados por S. A. E. el Príncipe y Gran Maestre Frey Matthew Festing y aprobados por el Soberano Consejo el 18 de febrero de 2011, pág. 65. La Comisión Cardenalicia establecida por el Papa Pío XII, fue requerida para valorar el vínculo de la Promesa de Obediencia de la Segunda Clase de la Orden de Malta y manifestó que es más fuerte que la promesa de los Terciarios o de los Oblatos. Este dictum se reproduce en Fr Constantino GILARDI, O. P., "The Regulations and Commentary: Source of initial and continuing formation. Some fundamental guidelines», en Journal of Spirituality, Soberana y Militar Orden Hospitalaria de San Juan de Jerusalén, de Rodas y de Malta, 14, (2013).

${ }^{29}$ Artículo $8.1 \mathrm{C}$ de la Carta Constitucional y artículo 116 del Código de la Soberana y Militar Orden Hospitalaria de San Juan de Jerusalén, de Rodas y de Malta, promulgada el 27 de junio de 1961, reformada por el Capítulo General Extraordinario del 2830 de abril de 1997, publicada en el Boletín Oficial de la Orden, número especial, de 12 de enero de 1998.

${ }^{30}$ Annuario Pontificio, Città del Vaticano, 2015, págs. 1352 y 1411 y ss.

${ }^{31}$ GAMBI, Paolo. op. cit., págs.207-208. 


\section{LA ORGANIZACIÓN ACTUAL DE LA ORDEN DE MALTA COMO SUJETO DE DERECHO INTERNACIONAL}

En la actualidad la Orden de Malta se rige por una Carta Constitucional y un Código, promulgados en 27 de junio de 1961 y reformados por el Capítulo General Extraordinario de 28-30 de abril de 1997 y publicados en el Boletín Oficial de la Orden de 12 de enero de $1998^{32}$. Hay una organización central que viene constituida por:

El Poder Ejecutivo, que en la Orden está representado por el Gran Maestre asistido del Soberano Consejo, formado por cuatro Altos Cargos y seis Consejeros. Altos Cargos: El Gran Comendador; es el superior religioso de los Caballeros Profesos y de los Caballeros y Damas de Obediencia. El Gran Canciller; Ministro de Asuntos Exteriores es el jefe de la rama ejecutiva. Responsable de la política exterior y las misiones diplomáticas de la Orden, es también el Ministro de Interior y está a cargo de las relaciones con las 47 Asociaciones nacionales de la Orden en el mundo. Bajo la autoridad del Gran Maestre y de conformidad con la Carta Constitucional y el Código, es el encargado de la representación de la Orden en sus relaciones con terceros, de la dirección política y la administración interna, así como de la coordinación de las actividades del Gobierno de la Orden. El Gran Hospitalario: Ministro de Sanidad, Asuntos Sociales, Acción Humanitaria y Cooperación Internacional. Coordina y vigila las obras de los Prioratos, de las Asociaciones Nacionales y de las demás estructuras de la Orden en todo el mundo dedicadas a actividades caritativas y humanitarias, y vela por la aplicación de los principios cristianos en todas ellas. El Recibidor del Común Tesoro: Ministro de Hacienda, dirige la administración de las finanzas y bienes de la Orden, de acuerdo con el Gran Canciller, bajo la autoridad del Gran Maestre y la vigilancia del Tribunal de Cuentas.

Órganos de Gobierno:

Consejo Pleno de Estado: Se reúne para la elección del Gran Maestre y del Lugarteniente del Gran Maestre. El Soberano Consejo: Asiste al Gran Maestre en el gobierno de la Orden. Lo forman el Gran Maestre, los titulares de los cuatro Altos Cargos (Gran Comendador,

${ }^{32}$ Carta Constitucional y Código de la Soberana y Militar Orden Hospitalaria de San Juan de Jerusalén, de Rodas y de Malta, promulgada el 27 de junio de 1961, reformada por el Capítulo General Extraordinario del 28-30 de abril de 1997, publicada en el Boletín Oficial de la Orden, número especial, de 12 de enero de 1998. 
Gran Canciller, Gran Hospitalario y Recibidor del Común Tesoro) y otros seis miembros.

Órganos Consultivos y de Apoyo:

El Consejo de Gobierno: Órgano consultivo del Soberano Consejo sobre materia política, religiosa, hospitalaria e internacional. Lo convoca y preside el Gran Maestre. El Tribunal de Cuentas: Vigila y controla los ingresos y gastos y el patrimonio de la Orden. Consejo para las Comunicaciones: Supervisa las actividades de comunicación interna y externa de la Orden. Consejo o Consulta Jurídica: Es un órgano técnico consultivo colegiado que puede ser interpelado sobre cuestiones y problemas jurídicos de relevancia por el Gran Maestre. La Abogacía del Estado: Ejercita, según los dictados del Código, la asistencia legal y está constituida por profesionales independientes de reconocido prestigio, expertos en Derecho y conocedores de las tradiciones y costumbres de la Orden ${ }^{33}$.

El Poder Legislativo en la Orden está representado por el Capítulo General. Representa la suprema asamblea de Caballeros y se convoca cada cinco años para elegir a los miembros del Soberano Consejo, del Consejo de Gobierno y del Tribunal de Cuentas, con el fin de introducir eventuales modificaciones a la Carta Constitucional y al Código y tratar problemas importantes, como los que se refieren al estado espiritual, al programa de actividades y a las relaciones internacionales de la Orden. Se compone, entre otros, de los representantes de los organismos de la Orden en el mundo: Grandes Prioratos, Subprioratos y Asociaciones Nacionales.

El Poder Judicial en la Orden está representado por los Tribunales Magistrales. Ejercitan, según el Código, la función jurisdiccional de primera instancia y de apelación.

A su vez, la organización territorial o periférica de la Orden que en la actualidad cuenta con aproximadamente 13.500 miembros, 80.000 voluntarios formados y 25.000 empleados, está hoy en día organizada en Grandes Prioratos, Prioratos, Subprioratos y Asociaciones (Nacionales). La denominación Gran Priorato obedece a la costumbre o se adopta por acuerdo del Capítulo General. Hoy en día existen seis Grandes Prioratos: tres en Italia: Roma, Lombardía-Venecia, con sede en Venecia, Nápoles-Sicilia, con sede en Nápoles; uno en Bohemia, con sede en Praga; uno en Austria y uno en Inglaterra. Así mismo

\footnotetext{
${ }^{33}$ Toda la organización central de la Orden de Malta se puede consultar en español en: http://www.orderofmalta.int/la-orden-y-sus-instituciones/330/ gobierno/?lang=es
} 
existen seis Subprioratos: San Miguel, en Alemania (Colonia), San Oliverio Plunkett, en Irlanda (Dublín), San Jorge y Santiago, en España (Madrid); erigido por Decreto Magistral de 9.2.1990; Nuestra Señora de Filermo, en EE.UU. (San Francisco), Nuestra Señora de Lourdes, en EE.UU. (Nueva York) y La Inmaculada Concepción, en Australia (Melbourne).

Las Asociaciones se pueden crear en los diferentes territorios, generalmente son nacionales. Hoy en día existen 47 Asociaciones, en los siguientes países o territorios: En Europa hay 17: Alemania, Bélgica, Reino Unido, Escandinavia, Eslovenia, España (inscrita en el Ministerio de Asuntos Exteriores y Cooperación), Francia, Hungría, Irlanda, Italia, Malta, Mónaco, Holanda, Polonia, Portugal, Rumanía y Suiza. En América hay 26: Argentina, Bolivia, Brasileña de Rio de Janeiro, de Sao Paulo y sur de Brasil, de Brasilia y Norte de Brasil, Canadá, Chile, Colombia, Costa Rica, Cuba, República Dominicana, Ecuador, (EE. UU.): Americana (Nueva York), Occidental (San Francisco), Federal (Washington, DC), Guatemala, Honduras, México, Nicaragua, Panamá, Paraguay, Perú, Polonia, El Salvador, Uruguay y Venezuela. En Asia hay tres: Filipinas, Líbano y Singapur. En África hay una en Senegal. En Oceanía hay una en Australia ${ }^{34}$. La Orden también contó siempre con monjas Comendadoras Sanjuanistas desde la fundación en Jerusalén que llevaban el hospital de mujeres ${ }^{35}$.

\section{LA ACCIÓN EXTERIOR (LA ACTIVIDAD DIPLOMÁTICA). EVOLUCIÓN HISTÓRICO JURÍDICA}

La Orden, como hemos visto, es un sujeto de Derecho Internacional y ejerce funciones soberanas a tenor de la Carta Constitucional (CC art. 3.1). A su vez, proclama en el art. 5.3 de la CC que los acuerdos internacionales ratificados según el art. 15.2.h) de la CC son fuentes del Derecho Melitense. Su relación primordial es con la Santa Sede (art. 4 CC) en razón de que entre sus fines y, en primer lugar, figura la santificación de sus miembros al servicio de la Fe, el Santo Padre y la ayuda al prójimo (art. 2.1. CC). La misma se lleva a cabo a través de un Cardenal Patrono nombrado por la Santa Sede con facultades especiales que promueve las relaciones entre la Santa Sede y la Orden, entre otras funciones (art. 4.4. CC). Por su parte, la Orden

\footnotetext{
${ }^{34} \mathrm{http}: / / w w w . o r d e r o f m a l t a . i n t / l a-o r d e n-e n-e l-m u n d o /$ ?lang=es\&continente=europa y sucesivos continentes en las pestañas correspondientes del enlace.

$35 \mathrm{http}: / / w w w . o r d e r o f m a l t a . i n t / l a-o r d e n-y-s u s-i n s t i t u c i o n e s / e s p i r i t u a l i d a d / 46387 /$ las-monjas-de-la-orden-de-malta/?lang=es
} 
nombra una representación diplomática ante la Santa Sede según las normas del Derecho Internacional (art. 4.5 CC).

Si bien su naturaleza religiosa no excluye el ejercicio de las prerrogativas soberanas que corresponden a la Orden en cuanto sujeto de Derecho Internacional reconocido por los Estados. Emite pasaportes para sus agentes diplomáticos ${ }^{36}$ (ejercitando así otra prerrogativa soberana), los cuales son reconocidos incluso por países con los que la Orden no mantiene relaciones diplomáticas ${ }^{37}$, reconociendo así indirectamente su soberanía.

En sus sedes extraterritoriales de Roma, el Gran Maestre recibe oficialmente a los Embajadores y ministros plenipotenciarios en los actos de presentación de sus cartas credenciales y en ellas residen los Altos Cargos del Soberano Consejo. Es conveniente precisar que la extraterritorialidad no es equivalente a territorio estatal, sino asimilable a la extraterritorialidad de las sedes diplomáticas. En dichas sedes se reúnen los Capítulos Generales y están ubicados los Tribunales de Justicia Magistrales, el Tribunal de Cuentas, el Correo Magistral y la Ceca. La Orden tiene su servicio postal y emite sellos desde 1966, habiendo firmado acuerdos postales con más de cincuenta países, incluso con aquellos con los que no mantiene relaciones diplomáticas. Tiene y emplea en sus relaciones con los terceros, todos los signos externos y símbolos de Estado: bandera; la más antigua de Occidente, escudos, himno, etc.

Es competencia del Gran Maestre, previo voto decisorio del Soberano Consejo, ratificar los acuerdos internacionales, a tenor de la Carta Constitucional (art. 15.2.h). Sus órganos centrales en materia de acción exterior son el Gran Maestre y el Gran Canciller. Sus órganos periféricos las Embajadas y Delegaciones ante las 106 Estados y numerosas Organizaciones Internacionales con las que mantiene relaciones en la actualidad. El Gran Canciller y Ministro de Asuntos Exteriores es el jefe de la rama ejecutiva (art. 18 CC). Responsable de la política exterior y las misiones diplomáticas de la Orden, es también el Ministro de Interior y está a cargo de las relaciones con las 47 Asociaciones nacionales de la Orden en el mundo. Es ayudado por uno o más secretarios generales nombrados por el Gran Maestre a propuesta del Gran Canciller, previo voto decisorio del Soberano Consejo y su cargo dura lo que el del Gran Canciller (art. 151 Código). Las representaciones diplomáticas dependen del Gran Canciller (art. 154

\footnotetext{
${ }^{36}$ El pasaporte diplomático de la Orden de Malta se instituyó por Decreto de la Lugartenencia, n. ${ }^{\circ} 60$, de 2 de julio de 1956, sólo para la misión diplomática.

${ }^{37}$ Es el caso de EE.UU., Alemania, Francia, Grecia y Jordania.
} 
Código). Bajo la autoridad del Gran Maestre y de conformidad con la Carta Constitucional y el Código, es el encargado de la representación activa y pasiva de la Orden en sus relaciones con terceros, de la dirección política y la administración interna, así como de la coordinación de las actividades del Gobierno de la Orden (art. 152 Código).

Los Jefes de las Misiones de la Orden representan al Gran Maestre ante los Gobiernos ante los que están acreditados. Aun cuando, en los respectivos Estados, existan estructuras propias de la Orden, ellos tratan los asuntos de que han sido encargados por el Gran Maestre, de manera independiente y bajo su propia responsabilidad (art. 154 Código). El nombramiento y la revocación de los representantes diplomáticos compete al Gran Maestre, a propuesta del Gran Canciller, oído el Soberano Consejo (art. 154 Código). Su duración en el cargo es de cuatro años renovables por iguales periodos de tiempo (art. 154 Código). La red diplomática de la Orden de Malta es una manifestación de su soberanía. Es a través del establecimiento y el mantenimiento de las relaciones diplomáticas con la Orden, como la Comunidad Internacional reconoce su soberanía, aunque en la actualidad no disponga de territorio. Su red diplomática deriva del derecho de legación de la Orden. Es un instrumento de sus relaciones públicas y de su comunicación, que permite gracias a los contactos diplomáticos bi y multilaterales dar a conocer mejor a la Orden y sus actividades sanitarias y humanitarias a los gobiernos y Organizaciones Internacionales.

Resumidamente las funciones de una misión diplomática son las de: representar, proteger, negociar, informarse y fomentar. Todas ellas le son de aplicación a las representaciones de la Orden de Malta. La tarea principal de las misiones diplomáticas bilaterales es dar testimonio y confirmar el carácter internacional y la soberanía de la Orden de Malta y el transmitirlo a las autoridades locales y a la opinión pública $^{38}$. A parte de las funciones generales de toda Misión Diplomática $^{39}$. Es a su vez el instrumento principal de comunicación entre el Gran Magisterio y las autoridades locales en lo que concierne a las actividades, intereses y la posición de la Orden. La misión diplomática a su vez informa al Gran Magisterio de los hechos relevantes para la diplomacia de la Orden que tengan lugar en el país de destino donde está acreditado.

${ }^{38}$ Manuel Diplomatique de L'Ordre Souverain Militaire Hospitalier de Saint-Jean de Jérusalem de Rhodes et de Malte, Roma, 2014.

${ }^{39}$ VILARIÑO PINTOS, Eduardo. Curso de Derecho Diplomático y Consular, Madrid, 2011, págs. 21-30. 
Las misiones diplomáticas multilaterales tienen como misión principal transmitir al Gran Magisterio la información sobre las actividades de las Organizaciones Internacionales e informar a estas y a sus miembros, observadores y ONG sobre las actividades de la Orden. En particular donde exista una colaboración sobre el terreno. Prevenir al Gran Magisterio sobre cuestiones o temas de discusión sobre los que la Orden podría o debería estar implicada.

Las características específicas de la Diplomacia de la Orden son las siguientes ${ }^{40}$ :

- La Orden es al tiempo una Orden religiosa laica y un sujeto de Derecho Internacional, que ejerce funciones de Estado soberano. Como tal ente soberano, ha sido siempre reconocido incluso después de la pérdida de Malta.

- Sus miembros son católicos que se rigen por los dos principios de la Orden Obsequium pauperum y Tuitio fidei.

- El servicio diplomático de la Orden se apoya en el compromiso personal de los miembros de la Orden que aceptan consagrar una parte de su tiempo a la representación exterior de la misma sin remuneración alguna. Siendo además a su cargo los costes de la misión (administración, traslados, representación, etc.).

- En ciertos países coexiste con un Gran Priorato o con una Asociación Nacional o con ambas u otros organismos de la Orden.

- Los agentes diplomáticos de la Orden son los oídos, ojos y boca del Gran Magisterio. Además de defender los intereses de la Orden, deben tener en cuenta que no tienen territorio que defender, ni intereses comerciales que promover y no están envueltos en conflictos internacionales ni en debates políticos. No deben hacer declaraciones políticas.

- Esta posición particular le permite mantenerse neutral e imparcial y ejercer su misión a favor de las necesidades sin distinción de religión, raza, origen o edad.

- Posee la Orden además una misión espiritual y es la heredera de una larga y gloriosa tradición a favor de los pobres y de los enfermos.

${ }^{40}$ Manuel Diplomatique de L'Ordre Souverain Militaire Hospitalier de Saint-Jean de Jérusalem de Rhodes et de Malte, Roma, 2014. 
Como hemos mencionado, la Orden tiene sus símbolos, tuvo sus fuerzas militares propias e hizo la guerra y acuña su moneda desde 1961 sólo con valor numismático. Con anterioridad, lo hizo desde 1308 durante su establecimiento en Rodas y prosiguió haciéndolo en Malta hasta 1798, emite sellos desde 1966 (con valor postal y filatélico) y mantiene relaciones diplomáticas con otros Estados.

El Derecho Internacional moderno admitió la existencia de un sujeto constituido de conformidad con normas vigentes antes de su formación y le reconoció una personalidad jurídica propia, diferente a la de los Estados. Además de la personalidad jurídica internacional y de los derechos de legación, es presupuesto para el establecimiento de relaciones diplomáticas que los sujetos que desean establecerlas se hayan reconocido recíprocamente y entre Estados que se haya reconocido el Estado y el Gobierno.

Desde 1446 en que el Papa reconoce en la persona del Gran Maestre al Príncipe Soberano de Rodas ${ }^{41}$, la diplomacia melitense no paró de desarrollarse. Al principio, a través de Misiones Especiales, más adelante con Misiones Permanentes. Antes de finales del siglo XVII la Orden intercambió embajadores con Francia, España, Rusia, Venecia, Baviera, Países Bajos, Cerdeña, Portugal y Prusia. En el periodo 17641815 estaban acreditados en París, Viena, Roma, Madrid, Lisboa, Cerdeña, Venecia, Múnich (Baviera), Berlín (Prusia), La Haya (Países Bajos), Varsovia (Polonia) y Moscú (Rusia). La orientación de la acción diplomática tras la pérdida de Malta era lograr la restauración del dominio territorial perdido. Más adelante, la Orden asumió que tal circunstancia no era ya viable y reorientó su acción exterior.

La distinción entre la diplomacia Vaticana y la de la Orden es clara y nunca un nuncio representa a la Orden, ni la Santa Sede interviene en modo alguno en las convenciones internacionales de la Orden. En el ámbito de la organización interna la Santa Sede no interviene en modo alguno, salvo para tramitar las dispensas que en ocasiones

${ }^{41}$ Por Bula del Papa Nicolás V, de 22 de febrero de 1446, el Gran Maestre Fray Fulco de Villaret fue reconocido como Príncipe soberano de Rodas. A nuestro juicio, es el primer documento que reconoce formalmente el carácter soberano de la Orden, ya que el nombramiento de Príncipe del Sacro Romano Imperio hecho por el Emperador del Sacro Romano Imperio Romano Rodolfo II, mediante diploma de 20 de marzo de 1607, ratificado por Fernando II, el 16 de julio de 1620, confiriéndole el rango de Alteza Serenísima, nombramiento nuevamente reconocido por el Emperador Francisco José en 1880, son al igual que la concesión del título, dignidad o rango de Cardenal de la Iglesia Católica de Roma, con tratamiento de Eminencia, concedido por el Papa Urbano VIII, el 10 de julio de 1630 y ratificado por el Papa León XIII, en 1888, tratamientos de carácter honorífico o protocolario. 
son necesarias para que caballeros no profesos puedan desempeñar cargos previstos en la normativa interna para ellos.

La transformación fundamental que experimenta la Comunidad Internacional a partir de los Tratados de Münster y Osnabrück (en Westfalia 1647-48), denominados por ello Paz de Westfalia, no alteró ni modificó la personalidad jurídica de la Orden de Malta que continuó siendo reconocida como un ente soberano por los Estados. Es decir, que aún tras el cambio de paradigma, la personalidad jurídica de la Orden no se vio alterada. Es más, en el periodo más turbulento de su larga historia, es decir, después de $1798^{42}$ y hasta 1834 , conservó su capacidad para concluir Tratados Internacionales. Así incluso en las Capitulaciones de 12.06.1798 (impuestas por Napoleón) se reconocía implícitamente la continuidad de la soberanía de la Orden. Esta situación muestra con claridad que:

1. La Orden de Malta y los Estados contratantes se presentan en el contexto de los diversos Tratados en un plano de igualdad o paridad.

2. En la gran mayoría de dichos Tratados, la Orden es expresamente calificada de «Soberana».

${ }^{42}$ El 15 de enero de 1779 la Orden de Malta firma una Convención de amistad con Rusia que establecía un nuevo Gran Priorato en dicho país y designa al Zar «Protector de la Orden». Esta situación vino motivada por la fiebre revolucionaria que asolaba Europa y frente a la cual el Zar Pablo I deseaba, a pesar de la tradicional hostilidad hacia la Iglesia Católica, ofrecerle su apoyo al Sumo Pontífice y a la Orden para que las fuerzas conservadoras de Occidente pudiesen detener la ola revolucionaria, sumado al afán de Rusia de llegar al Mediterráneo, siendo Malta un punto estratégico para las ambiciones rusas. Por su parte, la Orden había entablado conversaciones con Rusia, ya que con el desmembramiento de Polonia, el Gran Priorato de Polonia fundado en 1774, había pasado al control de Rusia. Esta situación dio lugar a que Francia, sintiéndose amenazada por la situación estratégica de Malta en el Mediterráneo y el evidente acercamiento de la Orden a potencias enemigas, la determinase a apoderarse de la isla, aprovechando la situación enrarecida política y socialmente de la isla, motivada por razones económicas, religiosas y nacionalistas. Es en ese momento, cuando se produce el denominado golpe de estado ruso de 1799 a 1801; de brevísima duración. El 21 de septiembre de 1799 el Emperador Pablo I de Rusia tomó la Orden bajo su protección. El 12 de octubre el Gran Maestre formuló su protesta ante todas las cortes europeas y el 7 de noviembre de 1799, el Zar se hizo proclamar Gran Maestre (¡laico, casado y ortodoxo!) por el Gran Priorato de Rusia de religión ortodoxa. En 1801 su sucesor Alejandro I ayudo a la Orden a recuperar un gobierno legítimo y renunció al título de Gran Maestre. Con posterioridad, por Decretos de 20.01 y 1.02.1817 el Consejo de Ministros de Rusia suprimió los Grandes Prioratos de Rusia renunciando el zar Alejandro I a toda injerencia en la Orden y devolviendo las insignias y el sello de la Orden. Por su parte, el Papa Pío VII, por un Breve de 16 de octubre de 1802, nombró al Bailío Berthelemy Ruspoli Gran Maestre. Aunque sorprendentemente la Orden de Malta no lo relaciona entre su Grandes Maestres, a pesar de que, al parecer, en los archivos vaticanos consta su nombramiento. 
3. No todos los Estados con los que la Orden ha suscrito los Tratados habían reconocido expresa y previamente la soberanía de la Orden y establecido en consecuencia relaciones diplomáticas.

4. La forma de los Tratados firmados con la Orden, es la usual en los acuerdos internacionales entre Estados.

5. No existe en dichos Tratados ninguna cláusula que excluya expresamente la aplicación del Derecho Internacional.

En consecuencia, hay que reconocer que la Orden además del derecho de legación activa y pasiva, goza de los atributos de la soberanía y, con ello, de la capacidad de contraer acuerdos internacionales y concurrir así a la formación del Derecho Internacional. Según se ha indicado ya que la Orden mantiene relaciones diplomáticas con 106 Estados de los casi 200 Estados oficialmente reconocidos y con numerosas Organizaciones Internacionales ${ }^{43}$, sin olvidar que su actividad diplomática viene de atrás.

Con la ocupación Napoleónica de la isla de Malta la Orden perdió sus derechos de soberanía y propiedad sobre la isla, quedando sin súbditos territoriales. A pesar de la crisis que ello supuso para la Orden, los Estados siguieron tratando con ella a través de sus representantes como representantes de un Estado soberano hasta el día de hoy en que su presencia en la Comunidad Internacional es probablemente más pujante que nunca.

\section{CONCLUSIONES}

A) La Orden ejerce su soberanía en una esfera más amplia de la que se produce en las sedes diplomáticas, que aunque gocen de extraterritorialidad ven limitadas a la esfera administrativa las garantías derivadas de la inmunidad; la Orden en cambio, se vale de la extraterritorialidad para cumplir los propios actos de autodeterminación que son los de los Estados, a saber, actos legislativos, judiciales y ejecutivos.

B) La Orden es un sujeto internacional originario actualmente estructurado de manera similar a los Estados. La Orden a través de sus órganos ejerce los poderes propios de un Estado. El poder legislativo a través del Capítulo General; el ejecutivo, por el Gran Maestre y el Soberano Consejo y, el judicial, a través de los Tribunales Magistra-

${ }^{43}$ Para una consulta actualizada en español de las relaciones internacionales de la Orden, ver: http://www.orderofmalta.int/noticias/?anno=2015\&lang=es

(C) UNED. Revista de Derecho UNED, núm. 17, 2015 
les, cuyas sentencias tienen ejecutoriedad en Italia (donde las sedes de la Orden constituyen un enclave extraterritorial).

C) La Orden al carecer de territorio no tiene súbditos territoriales como le ocurre a la Santa Sede. No tiene una población en sentido ordinario, ni ciudadanos. En la Orden de forma similar, sus miembros son además ciudadanos de otros Estados, pero sí son súbditos institucionales, en cuanto que pertenecen a la Comunidad Hospitalaria y están obligados a la observancia del Código y la Carta Constitucional. Esto no implica una doble nacionalidad, de hecho ni de derecho, porque la Orden es una institución de carácter internacional o mejor dicho supranacional. Cuando la Orden tuvo territorio (Rodas y Malta) también estaban perfectamente diferenciados los súbditos territoriales de los institucionales.

D) La Orden es soberana en sus relaciones internacionales y en su propio ordenamiento interno. Dispone de un gobierno que no deriva de ningún otro poder y que se impone por fuerza a sus súbditos. Al propio tiempo, dispone de un sistema de normas jurídicas que tiene en sí mismo la propia justificación y un poder judicial que decide la aplicación de las normas del ordenamiento en caso de controversia.

E) La naturaleza peculiar de entidad soberana supranacional, propia de las órdenes militares del Medievo, nunca ha sido puesta en discusión. Los Estados reconocen su soberanía aún en ausencia de base territorial. 